\title{
The Philosophic Interpretation of a Community of Shared Future for Mankind from the Perspective of the Marxist Philosophy
}

\author{
Shiren Liu \\ College of Marxism, College of Politics and Law, Sichuan University of Arts and Science, Dazhou, China \\ Email: 44699722@qq.com
}

How to cite this paper: Liu, S.R. (2019) The Philosophic Interpretation of a Community of Shared Future for Mankind from the Perspective of the Marxist Philosophy. Open Access Library Journal, 6: e5541. https://doi.org/10.4236/oalib.1105541

Received: June 13, 2019

Accepted: July 1, 2019

Published: July 4, 2019

Copyright $\odot 2019$ by author(s) and Open Access Library Inc.

This work is licensed under the Creative Commons Attribution International License (CC BY 4.0).

http://creativecommons.org/licenses/by/4.0/

\begin{abstract}
The concept of a Community of Shared Future for Mankind is proposed by Chairman Xi Jinping under the background of complicated and changeable international environment, rapidly development of Chinese economy, and great change in world political and economic situation. This concept is the new development of Marxism philosophy in the $21^{\text {st }}$ century, demonstrating the basic spirit and essence of Marxism philosophy. This paper explains the spirit of Marxism in the concept of community of shared future of mankind, the method of analyzing problems, the diplomatic concept of China in its peaceful rise in the concept of community of shared future of mankind from the perspective of Marxist philosophy, and the value of Chinese. The author holds that this concept analyzes the relationship between parts and whole, one relationship of the those three relationships of current world, aims to build a highly harmonious and unified world, advocates a diversified and unified world, coordinates parts in various relations, and resolves all kinds of conflict, with the aim to make humans into a more harmonious developing situation. This is not only in line with the general trend of world development, but also in line with the Chinese pursuit of "peaceful coexistence".
\end{abstract}

\section{Subject Areas}

Library, Intelligence and Philology, Literature

\section{Keywords}

Marxism Philosophy, A Community of Shared Future for Mankind, Philosophic Interpretation

\section{Introduction}

"A Community of Shared Future for Mankind" by Xi Jinping is a philosophical 
concept in line with traditional Chinese values in the face of complex and changing global environment in the $21^{\text {st }}$ century. This concept is not only the inheritance of the essence of traditional Chinese culture, but also innovation and development of the theoretical system of Marxism philosophy. It is the development of Marxism philosophy in the $21^{\text {st }}$ century. "The concept of a community of shared future for mankind is an in-depth reflection on the key problems of Marxism philosophy, and once it is put forward, it gets people's attention and heated discussion" [1]. The concept of a community of shared future for mankind highlights that in current situation human being should resolve and decrease conflicts on the basis of a holistic understanding of the world, bring mankind into a more harmonious stage, promote human civilization to a higher level, and achieve long-term stability and harmonious development of the whole mankind. This concept embodies Marxist understanding of the law of society development, the significance of theory to practice, and the promoting role of contradictory identity in the development of thing, thus putting forward the idea of the unity of opposite. The fate of human beings is a holistic, systematic and connected unity, and Chairman Xi Jinping emphasizes that China should not only solve their own problems, but also actively participate in global governance and shoulder their responsibility as a big country. China not only wants to bring happiness to Chinese people, but also benefit the people of the world, which set an example to those countries who want independence and rapid development at the same time. It can be said that a community of shared future for mankind is a proposition of great philosophical significance. It not only absorbs the essence of Chinese traditional culture, but also highlights the significance of Marxism in modern times.

A community of shared future for mankind appears at $21^{\text {st }}$ century at the background of countries' rapid development all over the world with various uncertain factors; meanwhile, the comprehensive national strength of China has improved greatly, both in the material and spiritual aspects. Marxist theory, as the core of the national ideology, is under great development. Theory of Marxism is an open system, and the communist party is willing to absorb everything useful to enrich the theory of Marxist. Chinese communists stress theoretical innovation, keeping pace with times, seeking truth from facts and analyzing specific problems in a case-by-case manner. They combine Marxist's general theory with China's reality and constantly promote theoretical innovation in practice, which is the source of vitality of the theory of Marxism.

A community of shared future for mankind is with rich connotations, which are represented in the following aspects. First, a community of shared future for mankind advocates equality among countries against hegemony. All countries, no mater big or small, should be respected. Big country can not interfere in other country's domestic affairs. Second, a community of shared future for mankind emphasizes the interconnectedness of people from different countries. Only by upholding justice and pursuing mutual interests and strengthening cooperation can human beings advance the progress and development of mankind as a whole. 
Third, a community of shared future for mankind holds that low-consuming and sustainable development. Earth is the only inhabitant for human being, which deserves the protection of all counties all over the planet. Fourth, countries should cooperate with each other to improve their ability of governance, concern others' core interests, and from a harmonious international relation. In addition, there are many other aspects, this paper believes that these four aspects mentioned above are the most important.

\section{The Concept of a Community of Shared Future for Mankind Represents the Character of Interconnection of Marxism Theory}

Marxism holds that the human beings lives in a world where everything is interconnected with each other, and nothing isolated. With the advancement of human world, their fate is strongly interconnected with each other. Mankind's ability of changing nature for their interest is increasing, while the destroy to nature for their activities is becoming stronger and stronger, with the tendency of showing global influence. The rapid development of science and technology accelerates the process of globalization which drives the globalization in various fields of mankind all over the world. The development of information technology reduces the cost of telecommunication, and improves the efficiency of telecommunication, making the world a global village. The economic crisis since 2008 is the best example of globalization. When the global economic crisis comes, no country can escape. It is a world where everything connects with one another, thus the whole mankind belongs to a community. All counties should cooperate in order to survive the economic crisis. For example, Chairman Xi Jinping put forward "One Belt and One Silk", which stimulates the development of the countries along this line, and many developing countries get the chance to build their infrastructures, like airports, highways, ports. Many countries have strengthened the ties with China in the idea of "Cooperation and share, Mutual benefit", which in turn stimulates the growth of world trade, and drives the development of China and many countries, so all counties must work together for a better future. Therefore, in order to solve current problems, everyone all over the world should work together, then it is appropriate to form the concept of a Community of Shared Future for Mankind.

\section{A Community of Shared Future for Mankind Analyzes the Relationship of the Whole and Part of the Real World}

A community of Shared future for mankind is a complex concept put forward after analyzing the three-layer relations between the whole and parts of the real world, namely, the relationship of the world and mankind, the relationship between countries all over the world, and the relationship of government and its people. The earth is a whole, and human as a part of the whole, live in this whole system. At the same time, human's activities will influence the environment they 
live, which can be seen from climate change, air pollution, energy use. Now human's living environment is on the edge, "the earth is home to all humans, and humans have no other choice but to cherish it", "Humans should be responsible not only for ourselves but also for their next generation" [2] (p. 538). Humans can not sacrifice environment for their own interest, and they need learn to co-exist with the environment. Take a look at all countries all over the world, with the trend of economic globalization, all countries are interconnected with each other, forming a unity. "Economic globalization has become a trend that no body can stop, which make the prosperous in trade, investment, talents and technology" [2] (p. 543).

History tells us that the more prosperous the world trade is, the more developed the world will be, and vise versa. Each government should initiate to join the trend of economic globalization, promote the development of their own counties and others, benefit their own people and others. With the rapid development of information technology, the link between each county have become closer, and the values are also presented the pluralistic trend, which causes difficulties to governance in some countries; with the enhancement of people's rights consciousness, the relationship between the government and their people in some countries are becoming tense. Each government should always give priority to the rights of the people and protect human rights in handling domestic problems [2] (p. 546). Each government should strive to improve people's livelihood, enhance people's rights, strengthen the construction of the legal system, improve people's living standards, and benefit their own people as well as the people of other countries.

\section{A Community of Shared Future for Mankind Advocates Harmonious Unity of Opposites under the Premise of Diversity}

Marxism views the world from the perspective of dialectics, and holds that the development of everything is ultimately driven by the contradictions, which contains two aspects of opposite and unity, namely the unity and conflict of contradictions, and the opposites and unity of both sides of contradictions jointly promote the development of everything. The current world is a unity of contradictions. Countries are both opposed and dependent on each other. There is competition in cooperation, and cooperation in competition. A community of shared future of mankind emphasizes competition under the constraint of civilization, which is a kind of unity of opposites.

Current world is a diversified unity with different history and culture, different national characters which at the same time make the current world full of contradictions and conflicts. Then it is necessary to solve all kinds of conflicts and frictions through dialogue. For example, Chairman Xi Jinping said that the ideal relationship between countries is "Countries in different sizes can co-exist with each other, and benefit from each other, in order to be prosperous together. Big countries and small countries should treat each other as equals and strike a 
balance between justice and interests. Justice should be more important than interests" [2] (p. 532).

Humans should give full consideration to the diversity of current world. Current world can be colorful because of the existence of various civilizations. "There is no superior or inferior civilization, only distinctive features and different regions. Differences among civilizations should not be a source of conflict, but a driving force for the progress of human civilization" [2] (p. 544). Therefore, "a community of shared future for mankind emphasizes that all countries and nations in current world share the same destiny; then all countries should open the door to share their achievements with all nations in the world, communicate with each other to solve political conflicts, jointly promote economic development, deepen cultural exchanges, promote global cultural integration, and enhance the sense of honor and happiness" [3].

A community of shared future for mankind, the achievement of Marxism theory in the $21^{\text {st }}$ century, embodies the essence of Marxism. Shared future gives an answer to how to solve a series of problems not only for Chinese but also for people of other countries, shows the image of China as a responsible country, demonstrates Chinese value of "harmony", and displays the absorption of Chinese culture. There are all kinds of uncertainty, various disturbing factors in current world. Shared future gives full consideration to the interests of all countries, in an attempt to resolve conflicts and contradictions peacefully, to coordinate all parties of the interest relations, promote the development of all countries, and benefit people all over the world, so as to promote the development of mankind.

To sum up, a community of shared future of mankind is the inheritance and development of Marxism, which reflects Marxism's view the world, that is, to see the world from the perspective of interconnectedness and development, and use the positive side of interconnectedness to promote the development of one's country. The concept of a community of shared future for mankind also requires human beings to handle relationship of the whole and the part properly, improve the living environment of mankind constantly, care about the core interests of all countries, improve people's livelihood, and enhance the image and credibility of the government. This concept is extremely rich with traditional Chinese culture, and the art of governance, which are the focus of future research. All in all, the concept of a community of shared future for mankind is a complex one which deserves further research for a better understanding.

\section{Conflicts of Interest}

The author declares no conflicts of interest regarding the publication of this paper.

\section{References}

[1] He, L. (2016) Class of Marxism Philosophy and a Community of Shared Future for 
Mankind. Philosophy Research, No. 8, 3-9+128.

[2] Xi Jinping. (2018) Xi Jinping Governance. Vol. 2, Foreign Languages Press, Beijing.

[3] Zhao, B.M. and Li, B.Y. (2008) Xi Jinping Thought of a Community of Shared Future for Mankind in the New Era. Journal of Kaifeng Institute of Education, 38, $11-13+16$. 